This document is confidential and is proprietary to the American Chemical Society and its authors. Do not copy or disclose without written permission. If you have received this item in error, notify the sender and delete all copies.

\title{
Langerin-Heparin Interaction: Two Binding Sites for Small and Large Ligands as revealed by a combination of NMR Spectroscopy and Cross-Linking Mapping Experiments
}

\begin{tabular}{|r|l|}
\hline Journal: & Journal of the American Chemical Society \\
\hline Manuscript ID: & ja-2014-11529x.R1 \\
\hline Manuscript Type: & Article \\
\hline Date Submitted by the Author: & $27-$ Feb-2015 \\
\hline Complete List of Authors: & $\begin{array}{l}\text { Muñoz-García, Juan C.; Consejo Superior de Investigaciones Cientificas and } \\
\text { Universidad de Sevilla, Instituto de Investigaciones Quimicas } \\
\text { Chabrol, Eric; CNRS, Institut de Biologie Structurale, laboratoire des } \\
\text { protéines membranaires } \\
\text { Vives, Romain; CNRS, Institut de Biologie Structurale, laboratoire des } \\
\text { protéines membranaires } \\
\text { Thomas, Aline; CNRS, IBS } \\
\text { de Paz, Jose; Instituto de Investigaciones Quimicas, CSIC-USE, Grupo de } \\
\text { Carbohidratos } \\
\text { Rojo, Javier; CSIC, Instituto de Investigaciones Quimicas } \\
\text { Imberty, Anne; CERMAV-CNRS, } \\
\text { Fieschi, Frank; Structural Biology, Grenoble, } \\
\text { Nieto, Pedro; Instituto de Investigaciones Quimicas, Quimica Bioorganica } \\
\text { Angulo, Jesús; University of East Anglia, School of Pharmacy; Consejo } \\
\text { Superior de Investigaciones Cientificas and Universidad de Sevilla, Instituto } \\
\text { de Investigaciones Quimicas }\end{array}$ \\
\hline \hline
\end{tabular}

\section{SCHOLARONE ${ }^{\text {Im }}$}

Manuscripts 


1
2
3
4
5
6
7
8
9
10
11
12
13
14
15
16
17
18
19
20
21
22
23
24
25
26
27
28
29
30
31
32
33
34
35
36
37
38
39
40
59
50
50
49
50
51
52
53
44
54

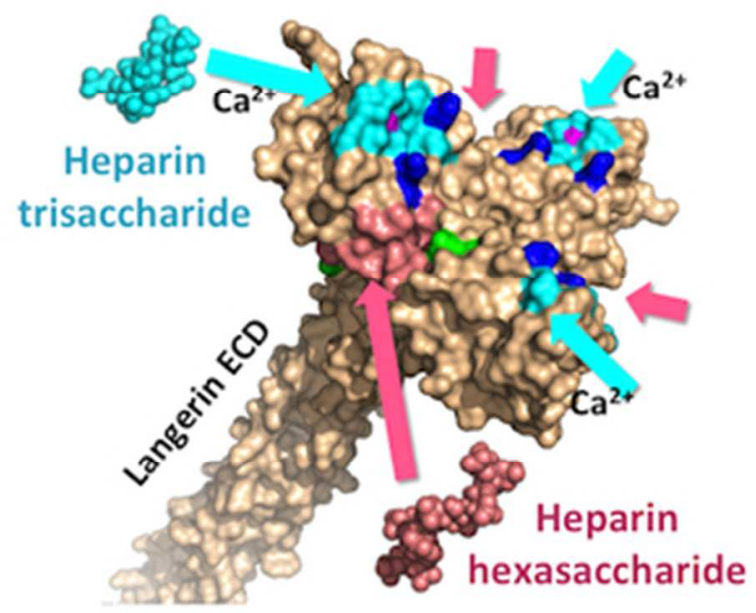

$48 \times 35 \mathrm{~mm}(200 \times 200$ DPI $)$ 


\section{INTRODUCTION}

Langerhans cells (LCs) constitute a subset of dendritic cells (DCs) located in the epithelium of mucosal tissues and epidermis ${ }^{1,2}$. Notably, LCs are the only epidermal cells to constitutively express major histocompatibility complex class II molecules ${ }^{3,4}$, CD1a molecules ${ }^{1}$, and the protein langerin ${ }^{5}$ at their cell surface. LCs play a key role in the induction of adaptive immune responses against pathogens or tumor by capturing and processing specific antigens and then migrating to draining lymph nodes to present processed antigens to $\mathrm{T}$ cells $^{6}$. In addition, although initially assumed to function as antigen-presenting cells (APCs), like dermal or stromal DCs ${ }^{7}$, there is accumulating evidence that LCs can also induce T regulatory cells, supporting the hypothesis that these cells could induce and maintain tolerance against self antigens, suggesting also a tolerogenic role ${ }^{8}$ for these cells in vivo.

A characteristic hallmark of LCs is the unique presence in the cytoplasm of penta-lamellar and zippered membranes defining rod-shaped structures, known as Birbeck granules (BGs) ${ }^{9}$, which are thought to be part of the endosomal recycling pathway, as they are subdomains of the endosomal compartment ${ }^{5}$. Due to their localization at the epithelium level, LCs were reported a few years ago to constitute the first natural barrier to HIV-1 particles ${ }^{10}$. Interestingly, instead of 
the common antigen-presenting cell role of DCs, LCs internalize HIV-1 virions into their BGs for subsequent elimination of the viral particles, upon sequestration of the virus by the C-type lectin langerin (CLEC4K) ${ }^{10}$. Furthermore, langerin has been shown to be the main protein responsible for BGs formation ${ }^{5}$. Thus, langerin has been presented as a key player in the natural barrier to HIV-1 transmission by LCs ${ }^{10}$.

Langerin is a transmembrane type II C-type lectin, almost exclusively expressed on epidermal LCs, and it is functionally competent in a trimeric form. Langerin features the classical $\mathrm{Ca}^{2+}$ dependent carbohydrate binding domain (CRD) of C-type lectin with an EPN motif characteristic for mannose specificity ${ }^{12}$. The crystal structure of the trimeric extracellular domain (ECD) that comprises the CRD and part of the neck domain demonstrated that the three binding sites are widely spaced and probably rigidly positioned in a manner reminiscent of mannose-binding proteins ${ }^{13}$. However, although the binding site in each CRD is relatively open as in mannose-binding proteins, glycan array results indicated that langerin shows preferential specificity to few oligosaccharides instead of broad binding to any mannose-terminated glycan as seen in other mannose-binding proteins ${ }^{13-17}$. Among the unusual specificity reported for langerin is its ability to bind to sulfated glycans and even, surprisingly, considering its specificity for mannose-based ligands, to galactose-6-sulfated glycans. The structures of several langerin-ligand complexes reveal that preferential binding results from a small number of favorable contacts with selected moieties of oligosaccharide ligands beyond the monosaccharides sitting in the primary binding site. In this regard, the binding site on langerin shares some of the features of that of DC-SIGN, although secondary contacts are less extensive ${ }^{16,17}$.

Langerin was recently reported to display, alongside its common $\mathrm{C}$-type lectin binding properties $\left(\mathrm{Ca}^{2+}\right.$ coordination of ligand at the CRD), a $\mathrm{Ca}^{2+}$-independent receptor profile for sulfated glycosaminoglycans (GAGs), in particular, heparin (HEP), heparan sulfate (HS), chondroitin sulfate (CS) and dermatan sulfate (DS) ${ }^{18}$. In that study, the trimeric state of langerin was demonstrated to be mandatory for binding, and a 3D docking model for langerin-HEP complex was proposed, which located the GAG binding site outside the classical $\mathrm{Ca}^{2+}$ specific site, at the interface between two adjacent CRD monomers in the trimer. The proposed model explained the observed $\mathrm{Ca}^{2+}$ independence of the HEP binding. Furthermore, experiments with HEP (molecular weights of 6 and $15 \mathrm{kDa}$ ), HS, CS and DS showed that: i) binding to langerin cannot be simply correlated to a net charge effect and ii) specific sulfation (D-GlcN6S and L-IdoA2S) strengthen the interaction $^{18}$.

In the context of BGs formation, essential for HIV-1 internalization and neutralization, putative models were previously proposed for the bridging role of langerin on the organization of membranes in these organelles ${ }^{19}$. Therefore, it seems appealing to speculate on sulfated GAGs playing a leading role on BGs organization by providing simultaneous interactions with facing trimers, thus possibly acting as stabilizers of the macromolecular complexes that lead to the characteristic membranes organizations within BGs.

Under this framework, we decided first, to confirm the binding of long HEP oligosaccharides to the groove at the langerinlangerin multimerization interface in the trimeric state of the protein, through crosslinking experiments using heparinbeads. And, second, to apply a reductionist approach to characterize the structural details of the molecular recognition of GAGs by langerin, by undertaking high-resolution NMR studies with small heparin-like oligosaccharides. The rationale was that large GAGs ( $>6 \mathrm{kDa}$ ) would lead to broad (fast relaxation) and degenerated signals, compromising the spectral resolution as to obtain useful structural information.
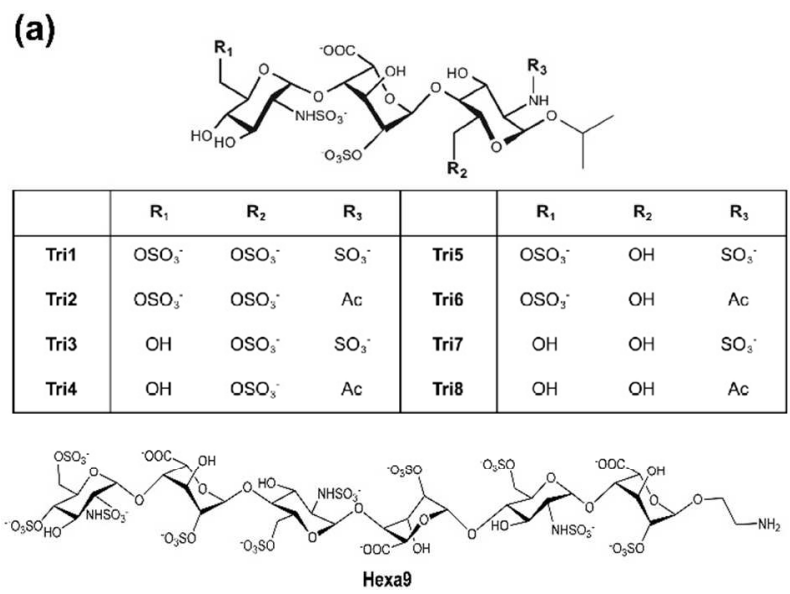

(b)

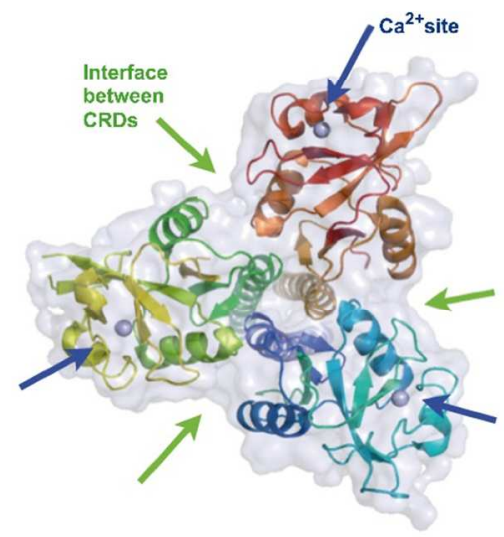

Scheme 1. (a) Heparin-like trisaccharides Tri1-Tri8 and Hexa9 studied in the present work (b) Cartoon showing the two different binding sites for ligands on langerin, repeated three times due to the threefold symmetry of the receptor.

Therefore, we have studied the molecular recognition of a set of 8 differently sulfated small HEP-like trisaccharides ${ }^{20}$ (Tri1Tri8, Scheme 1) by langerin extracellular domain (ECD, trimeric form), using NMR spectroscopy in solution. Their systematic variation in sulfation positions allows us to analyze the impact of the substitution pattern of GAGs on binding. In addition, aiming to test the effect of the length of the GAG ligand on binding, we have studied the interaction of langerin with a HEP hexasaccharide containing an extra sulfate group at position 4 of the non-reducing ring (Hexa9, Scheme 1) $)^{21}$. The introduction of a sulfate group at that position generates a non-natural sulfate distribution. This sulfation pattern precludes $\mathrm{Ca}^{2+}$ coordination at the CRD site since the equatorial hydroxyl group $\mathrm{OH} 4$ at the non-reducing end is not available for binding. Ligand-based NMR techniques, saturation transfer difference NMR spectroscopy (STD-NMR) and transferred-NOESY experiments, together with molecular 
dynamics simulations and docking calculations, have been employed.

In summary, this work reports on the surprising ligand size dependence of GAG binding to two different sites in langerin, defining at atomistic detail the boundaries at langerin trimeric interfaces involved in GAG molecular recognition, and describe the key contacts governing binding.

\section{MATERIALS AND METHODS}

HEP ligands. The synthesis of the ligands Tri1-Tri8 and Hexa9 have been previously described ${ }^{20,21}$.

Production of langerin ECD. Lg ECD constructs, comprising residues 68-328, were overexpressed as inclusion bodies, then refolded and purified to homogeneity in a functional form as already described ${ }^{18}$. Lg ECD was then concentrated after dialysis in buffer: $\mathrm{D}_{2} \mathrm{O}\left(150 \mathrm{mM} \mathrm{NaCl}, 4 \mathrm{mM} \mathrm{CaCl}{ }_{2}, 25 \mathrm{mM}\right.$ d-Tris, $\mathrm{pD}=8$ ).

Heparin-bead cross-linking experiment. Bead approach analyses were performed as previously described ${ }^{22}$. Briefly, HEP beads in 50mM MES, $150 \mathrm{mM} \mathrm{NaCl} \mathrm{pH5.5} \mathrm{were}$ activated with a mixture of $40 \mathrm{mM}$ 1-ethyl-3-(3dimethylaminopropyl) carbodiimide (EDC), $10 \mathrm{mM} \mathrm{N}$ hydroxysuccinimide (NHS) in 50mM MES, $150 \mathrm{mM} \mathrm{NaCl}$ $\mathrm{pH} 5.5$, for 10 minutes at room temperature. EDC/NHS in excess were inactivated by addition of $\beta$-mercaptoethanol (15 $\mathrm{mM}$ final) and removed by centrifugation. Beads were washed twice with PBS, and incubated with $30 \mu \mathrm{g} \operatorname{Lg}$ ECD $(1 \mu \mathrm{M}$ final concentration) in PBS for 2 hours at room temperature, under gentle agitation. The reaction was then quenched by addition of $1 \mathrm{M}$ Tris, $\mathrm{pH} 7.5 \quad(100 \mathrm{mM}$ Tris, final concentration) and beads were washed twice with PBS, 2 M $\mathrm{NaCl}$ to remove non-covalently bound material. Lg ECD bound to HEP beads complexes was denatured by heating at $60{ }^{\circ} \mathrm{C}$ in PBS, $2 \mathrm{M}$ Urea for 45 minutes, and digested overnight with thermolysine $(53 \mathrm{mIU})$ at $50{ }^{\circ} \mathrm{C}$, under agitation. Free peptides were removed by washing the beads 3 times with PBS, $2 \mathrm{M} \mathrm{NaCl}, 15 \mathrm{mM}$ B-mercaptoethanol, $1 \%$ Triton, and beads-bound peptides were sequenced using an Edman degradation automated protocol. Cross-linked residues were easily identified, as: (i) coupling prevented their elution, yielding a "blank" cycle during the sequencing; (ii) amino acid recovery yields dramatically dropped for the sequencing of downstream residues.

Nuclear Magnetic Resonance. NMR samples were prepared in $200 \mu \mathrm{L}$ of $99.9 \% \mathrm{D}_{2} \mathrm{O}$ buffer containing $25 \mathrm{mM}_{\text {Tris- }} \mathrm{d}_{11} \mathrm{pH}$ $8,150 \mathrm{mM} \mathrm{NaCl}$ and $4 \mathrm{mM} \mathrm{CaCl}{ }_{2}$. Protein concentrations of $105 \mu \mathrm{M}$ (Tri1-Tri8) and $54 \mu \mathrm{M}$ (Hexa9) were employed. On the ligand side, concentrations of 1.50 (Tri1-Tri8) and 1.16 $\mathrm{mM}$ (Hexa9) were used. Thus, protein to ligand ratios of 1:14 (Tri1-Tri8) and 1:21 (Hexa9) were employed. TransferredNOESY (tr-NOESY) and STD NMR experiments used for epitope mapping of Tri1-Tri8 were performed at $15{ }^{\circ} \mathrm{C}$ on a Bruker digital Avance $800 \mathrm{MHz}$ spectrometer equipped with a $8 \mathrm{~mm}$ inverse triple-resonance probe. In the case of Hexa9, the experiments were carried out at $10{ }^{\circ} \mathrm{C}$ on a Bruker Avance DRX $500 \mathrm{MHz}$ spectrometer equipped with a $5 \mathrm{~mm}$ inverse triple-resonance probe.

STD NMR experiments were carried out with solvent suppression and a $10 \mathrm{~ms}$ spin-lock filter after the $90^{\circ}$ pulse to reduce residual signals from the protein. For selective protein saturation, cascades of $49 \mathrm{~ms}$ Gaussian shaped pulses at a field strength of $50 \mathrm{~Hz}$ were employed, with a delay of $1 \mathrm{~ms}$ between successive pulses ${ }^{23}$. The on-resonance and offresonance frequencies were set to $6.8 \mathrm{ppm}$ and $40 \mathrm{ppm}$, respectively. Blank experiments were performed to assure the absence of direct saturation of the ligand proton signals. The relaxation delay was properly adjusted so that the experiment time length was kept constant $(6.1 \mathrm{~s})$. Depending on saturation time, STD NMR experiments were performed with 64/256 scans at $800 \mathrm{MHz}$, or $1 \mathrm{~K} / 2 \mathrm{~K} / 4 \mathrm{~K}$ scans at $500 \mathrm{MHz}$, in inverse relation to the saturation time.

STD amplification factors $\left(\mathrm{STD}-\mathrm{AF}_{0}\right)$ were calculated from the STD initial slopes. To do so, the evolution of the STD-AF with the saturation time $\left(\mathrm{t}_{\mathrm{sat}}\right)$ was fitted to the equation STD$\mathrm{AF}(t)=a(1-\exp (-b \mathrm{t}))$, where the parameter $a$ represents the asymptotic maximum of the STD build-up curve $\left(\mathrm{STD}^{\max }\right), b$ is a rate constant related to the relaxation properties of a given proton that measures the speed of the STD build-up $\left(\mathrm{k}_{\mathrm{sat}}\right)$, and $t$ is the saturation time $\left(t_{\text {sat }}\right)$. Thus, the STD-AF $F_{0}$ values were obtained as the product of the $a b$ coefficients.

To quantitatively compare the affinities of the eight HEP trisaccharides their STD initial slopes recorded under the same experimental conditions (105 $\mu \mathrm{M} \mathrm{Lg} \mathrm{ECD,} 1.5 \mathrm{mM}$ ligand, 25 $\mathrm{mM}$ Tris-d11 $\mathrm{pH} 8,150 \mathrm{mM} \mathrm{NaCl}$ and $4 \mathrm{mM} \mathrm{CaCl} 2,800$ $\mathrm{MHz}, 15^{\circ} \mathrm{C}$ ) were analyzed. The initial slopes of protons $\mathrm{H} 3$ and $\mathrm{H} 4$ of residue $\mathrm{C}$ (the most intense signals) were averaged. As the binding mode of Tri1-Tri8 to Lg ECD is the same, the orientations of $\mathrm{H} 3$ and $\mathrm{H} 4$ of residue $\mathrm{C}$ within the binding pocket (and hence their relative distances to protein protons) are rather similar for all the ligands. Under similar experimental conditions, differences in affinities can be detected by differences in STD initial slopes (variation in the fraction of bound ligand). For the affinity determination of the interaction of Tri1 with $\mathrm{Lg}$ ECD, a titration was carried out and the protocol of the binding isotherm of STD initial slopes was followed ${ }^{24}$. The experiments were carried out at $15^{\circ} \mathrm{C}$ on a $600 \mathrm{MHz}$ Avance III HD NMR spectrometer equipped with a cryoprobe. For each ligand concentration (from $200 \mu \mathrm{M}$ to $10 \mathrm{mM}$ ), six STD NMR experiments were recorded, with increasing saturation time $(0.5,1,2,3,4$, and $5 \mathrm{~s})$, accumulating 1-1.5 K scans. The buildup curves of the STD amplification factors were mathematically fitted to a monoexponential equation STD-AF $(t)=a(1-\exp (-b \mathrm{t}))$, and the initial slopes obtained. From these initial slopes, the binding isotherm was built (STD- $\mathrm{AF}_{0} v s$. ligand concentration), and the curve fitted to a Langmuir equation, from which we the $\mathrm{K}_{\mathrm{D}}$ value was determined. The final value was calculated as an average of measurements from different ligand protons $(\mathrm{H} 4 \mathrm{C}$, $\mathrm{H} 2 \mathrm{C}, \mathrm{H} 2 \mathrm{~A}$, and $\mathrm{CH}_{3}$ of isopropyl group).

Tr-NOESY experiments were performed using a phase sensitive pulse program with gradient pulses in the mixing time $^{25,26}$ and a relaxation delay of $1.5 \mathrm{~s}$. The experimental distances of the ligand in the bound state were derived from trNOESY experiments at $200 \mathrm{~ms}$ mixing time. First, each cross peak was divided by its corresponding diagonal peak, thus obtaining the normalized NOE volume. Each volume was divided by the mixing time to get a good approximation of the cross-relaxation rate $\sigma_{\mathrm{NOE}}$. Then, considering the Isolated Spin Pair Approximation (ISPA) ${ }^{27}$ and using the fixed $\mathrm{H} 1-\mathrm{H} 2$ distance at the non-reducing $\mathrm{GlcNHSO}_{3}{ }^{-}$ring (C) as reference $(2.5 \AA)$, the key inter-glycosidic proton-proton distances were 
calculated according to the expression $\mathrm{d}_{\mathrm{x}}=\mathrm{d}_{\mathrm{ref}} \cdot\left(\sigma_{\mathrm{ref}} / \sigma_{\mathrm{x}}\right)^{1 / 6}$, where $d_{x}$ is the unknown distance to be determined, $d_{\text {ref }}$ is the distance used as reference, and $\sigma_{\text {ref }}$ and $\sigma_{x}$ are the crossrelaxation rates of the reference and unknown distance, respectively.

Molecular modeling. Conformational sampling of Tri1-Tri8 and flexible Induced Fit Docking were carried out using the Glide protocol within the Schrodinger molecular modeling suite. The crystal structure of langerin complexed to laminaritriose $(\mathrm{pdb} \text { code } 3 \mathrm{P} 5 \mathrm{H})^{17}$ was used as the starting structure. A flexible induced fit protocol was carried out to obtain a Tri1-langerin complex. The obtained receptor was then used to dock the Tri1-Tri8 ligands using conformational sampling and flexible docking calculations. Molecular dynamics were run using AMBER 11 including the specific carbohydrate parameterization GLYCAM 06h. Extended details of the experimental conditions for molecular modeling can be found at the Supporting Information.

\section{RESULTS AND DISCUSSION}

Mapping the langerin heparin binding site using a heparin-bead cross-linking approach. To experimentally validate the previously proposed model for the interaction of Lg ECD with $6 \mathrm{kDa}$ HEP, ${ }^{18}$ we decided to identify the binding site using a specific experimental method (HEP-bead crosslinking, see Materials and Methods) designed to identify HEP/HS binding sites in proteins ${ }^{22}$. Analysis of Lg ECD using the heparin-beads approach yielded 3 peptides: $\mathrm{V}_{194}$ VSQGWKYFK $_{203}, \quad \mathrm{~F}_{204}$ KGNFYYF $_{209}$ and $\mathrm{L}_{211}$ IPKTWYSAE 220 , with cross-linking detected at the level of K203 and K214 (see Supporting Information, Figure S1). These results are therefore in agreement with the previously published data, which suggested using a molecular modeling approach, that for $6 \mathrm{kDa}$ HEP ligand the binding site was located at the interface formed by 2 CRDs and the neck domain (Scheme $1 \mathrm{~b}$ and Figure 1$)^{18}$.

It must be emphasized that the beads approach is designed to locate HEP/HS binding sites within proteins, and is not suited to specify all amino acids involved in the interaction. This technique relies on EDC/NHS cross-linking, which only reacts with primary amines, and therefore only lysine residues involved in HEP/HS binding could be identified. Further investigation will therefore be needed to analyze the contribution to binding of non-lysine residues located in this area. In addition, no cross-linking could be observed for two of the lysines comprised within the predicted HEP/HS binding site: K186 and K244. Again, we cannot rule out the involvement of these residues, as they might contribute to the interaction through electrostatic bonds with sulfate moieties of the polysaccharide and hence may be too distant from carboxyl groups in the HEP/HS/protein complex to allow cross-linking. Significantly, the two identified lysines (K203 and K214) were predicted to be at both ends of the predicted GAG binding site at the CRD interface within the Lg ECD (Figure 1). These heparin site mapping experiments thus remarkably support the original hypothesis that the HEP/HS binding site is distinct from the canonical C-type lectin binding site in langerin, and define a restricted sequence frame of potential future structural investigation using site directed mutagenesis.

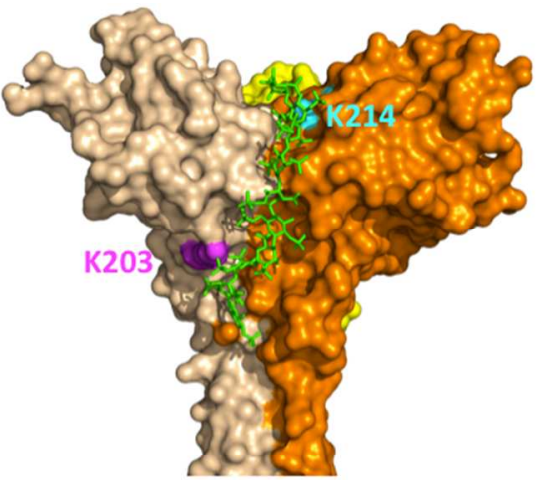

MGTISDVKTNVQLLKGRVDNISTLDSEIKKNSDGMEAAGVQIQMVNESLGYVRSOFLK LKTSVEKANAQIQILTRSWEEVSTLNAQIPELKSDLEKASALNTKIRALQGSLENMSKLLK RQNDILQVVSQGWKYFKGNFYYFS IPKTWYSAEQFCVSRNSHLTSVTSESEQEFLYK TAGGLIYWIGLTKAGMEGDWSWVDDTPFNKVQSARFWIPGEPNNAGNNEHCGNIK APSLQAWNDAPCDKTFLFICKRPYVPSEP

Figure 1. Top, 3D molecular model of the complex of $\mathrm{Lg}$ ECD with $6 \mathrm{kDa} \mathrm{HEP}^{18}$. Each of the three CRD monomers is in different color and the HEP molecule is in green. Residue K203 is in magenta, and residue K214 in cyan, both identified in the cross-linking experiment. Bottom, primary sequence of Lg ECD showing the peptides identified in the HEP-beads cross-linking approach. Results are representative of three independent experiments.

STD NMR experiments (I): the interaction of the HEP-like trisaccharides with langerin ECD is $\mathrm{Ca}^{2+}$-dependent. After the confirmation of the $\mathrm{Lg}$ ECD binding site for $6 \mathrm{kDa} H E P$, we started the structural studies to characterize the binding of the HEP-like Tri1-Tri8 trisaccharides to Lg ECD by STD NMR spectroscopy. The strong affinity $\left(\mathrm{EC}_{50}\right.$ of $\left.150 \mathrm{nM}\right)$ for 6 $\mathrm{kDa}$ HEP binding in the $\mathrm{Ca}^{2+}$-independent site, ${ }^{18}$ makes the STD NMR approach hardly applicable, as this experiment relies on a fast exchange between the free and the bound states, in the NMR relaxation time scale. On the other hand, the presence of bulky sulfate groups on the ligand increases the distances between protein and ligand protons in the bound state, reducing the efficiency of the magnetization transfer. Under these premises, our first interest was to test whether the binding of the trisaccharides would be observable by STD NMR experiments. Our second aim was to investigate the effect of the $\mathrm{Ca}^{2+}$ cations on the interactions.

In the presence of $\mathrm{Ca}^{2+}$ all ligands Tri1-Tri8 showed clear STD signals in the spectra on samples containing Lg ECD (Figure 2b, and Supporting Information Figure S2). This means that their binding is weaker than that of $6 \mathrm{kDa} H E P$, as for such strong binders no STD signals would be expected. Besides, and surprisingly, the addition of an excess of EDTA $(10 \mathrm{mM})$, to sequester the $\mathrm{Ca}^{2+}$ ions, did abolish the binding of the trisaccharides Tri1-Tri8 to $\mathrm{Lg}$ ECD, as no STD signals were then observed in the spectra (Figure 2c). 


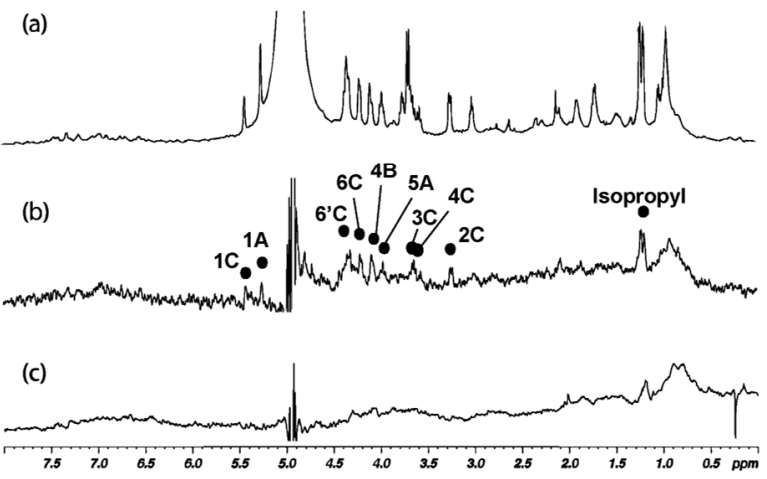

Figure 2. The interaction of HEP-like trisaccharides with $\mathrm{Lg}$ ECD is $\mathrm{Ca}^{2+}$-dependent. (a) $1 \mathrm{D}{ }^{1} \mathrm{H}$ NMR reference (offresonance) spectrum of Tri1 in the presence of $\operatorname{Lg}$ ECD. (b) 1D STD NMR spectrum of Tri1 in the presence of Lg ECD in $4 \mathrm{mM} \mathrm{Ca}^{2+}$ Tris-d $_{11}$ buffer. (c) 1D STD NMR spectrum of Tri1 in the presence of Lg ECD in 10 mM EDTA- $\mathrm{d}_{12}$ Tris- $\mathrm{d}_{11}$ buffer. Black circles mark ligand STD signals. In (c) the STD spectrum shows only the envelope of proton signals from the large protein.

These results strikingly differ from the previous observation of $\mathrm{Ca}^{2+}$-independent binding of longer HEP polysaccharides to $\mathrm{Lg} \mathrm{ECD}^{18}$. The molecular model proposed in that work, with binding to langerin taking place in an extended binding site only present in the trimeric form of the protein, different from the $\mathrm{Ca}^{2+}$-specific (Scheme 1b), ${ }^{18}$ has been confirmed in this work through the cross-linking experiments (Figure 1). However, the molecular recognition of the smaller trisaccharides Tri1-Tri8 by Lg ECD requires the presence of the divalent cation, suggesting a different site of binding, in which the $\mathrm{Ca}^{2+}$ ion must play an essential role.

STD NMR experiments (II): the interaction of HEP-like trisaccharides with langerin ECD is independent of their sulfation-pattern. To go in depth into the mode of binding of each trisaccharide, Tri1-Tri8, to Lg ECD, series of STD NMR experiments were carried out at high field $(800 \mathrm{MHz})$ varying the saturation time to monitor the growth of STD signals. Figure 3 shows the STD NMR experiment at $2 \mathrm{~s}$ saturation time (Figure 3a) as well as the build-up curves for the three sugar residues of Tri1 (Figure 3c; for the remaining ligands, Tri2-Tri8, see Supporting Information Figure S2). The data show that the residue receiving the largest amount of saturation from the protein is the glucosamine ring at the nonreducing end of the ligand (residue $\mathrm{C}$ ). A lower and rather homogeneous saturation is transferred to the remaining two other sugar rings ( $\mathrm{B}$ and $\mathrm{A}$ ).
From these STD build-up curves, we mapped out the main contacts of the ligands with langerin in the bound state (binding epitope) at high resolution, by determining the initial slopes of the curves and normalizing all the values within a given ligand by the highest one, to which arbitrarily a value of $100 \%$ was assigned. The use of initial slopes increases the accuracy of the method by avoiding the detrimental effects of different relaxation properties of the ligand protons on the determination of the binding epitope ${ }^{28}$. The results for Tri1 are shown in Figure 3b (Supporting Information Figure S2 for Tri2-Tri8).

Remarkably, all the ligands showed comparable patterns of STD distribution, all of them similar to Tril (Figure 3b, and Supporting Information Figure S2), within the experimental error. This means that the eight trisaccharides bind to Lg ECD with equivalent binding modes, irrespective of the different sulfation patterns of the ligands (Scheme 1). The data hence support that the variable sulfate groups along the trisaccharides series $(\mathrm{N}-$ and 6-O-sulfates of residue $\mathrm{A}$, and 6$\mathrm{O}$-sulfate of residue $\mathrm{C}$ ) are not essential for the interaction. The binding mode shared by the eight ligands, involve closest contacts with the protein surface at protons $\mathrm{H} 3, \mathrm{H} 4, \mathrm{H} 5$, and $\mathrm{H} 6$ of the non-reducing glucosamine ring $(\mathrm{GlcN}(\mathrm{C}))$. In all cases, $\mathrm{H} 4$ of this residue showed the largest saturation transfer (100\% relative STD) among the ligand protons, highlighting the importance of this part of the molecule for the molecular recognition by Lg ECD (Figure 3 and Supporting Information Figure S2).

As the variable functional groups $\left(R_{1}, R_{2}\right.$, and $R_{3}$ in Scheme 1$)$ did not impact the mode of binding of the ligands Tri1-Tri8, we wanted to test their influence on affinities. To that aim, we determined the dissociation constant for the interaction of langerin with Tri1, and carried out a quantitative comparison of affinities among the series of ligands in an approach based on their STD responses under the same experimental conditions. The latter (see Materials and Methods) revealed that all the trisaccharides show comparable affinities towards Lg ECD (see Supporting Information, Figure S3), in agreement with their similarity in binding modes and demonstrating again the absence of any significant impact on binding from the variation in functional groups along the series of ligands Tri1-Tri8. The affinity of Tri1, accurately determined by the recently proposed approach of the binding isotherm of STD initial slopes ${ }^{24}$ (Figure 4) is characterized by a $\mathrm{K}_{\mathrm{D}}$ of $490( \pm 50) \mu \mathrm{M}$. Thus, the affinity data indicate that langerin recognizes the HEP trisaccharides Tri1-Tri8 with comparable affinities with $K_{D}$ values in the range of $0.5 \mathrm{mM}$. 
(a)

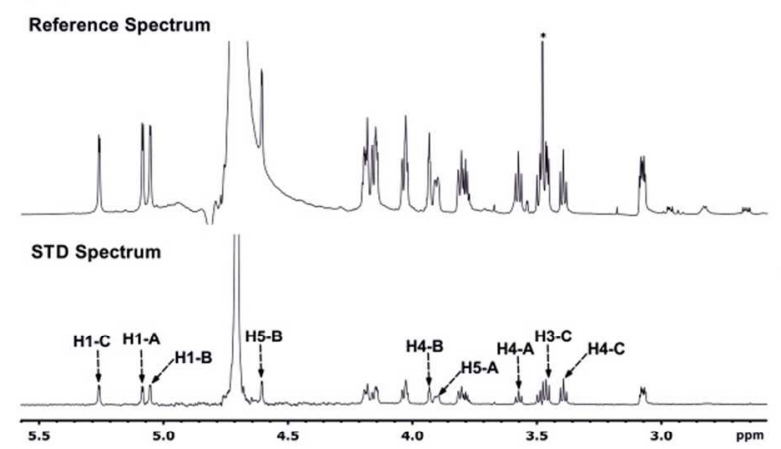

(c) (b)

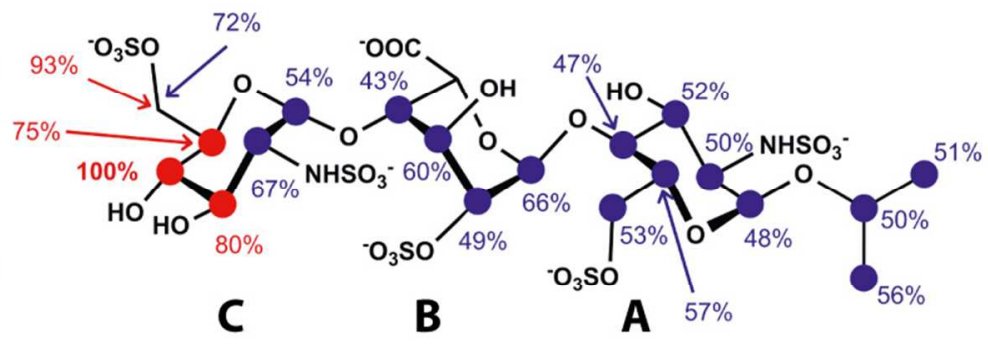

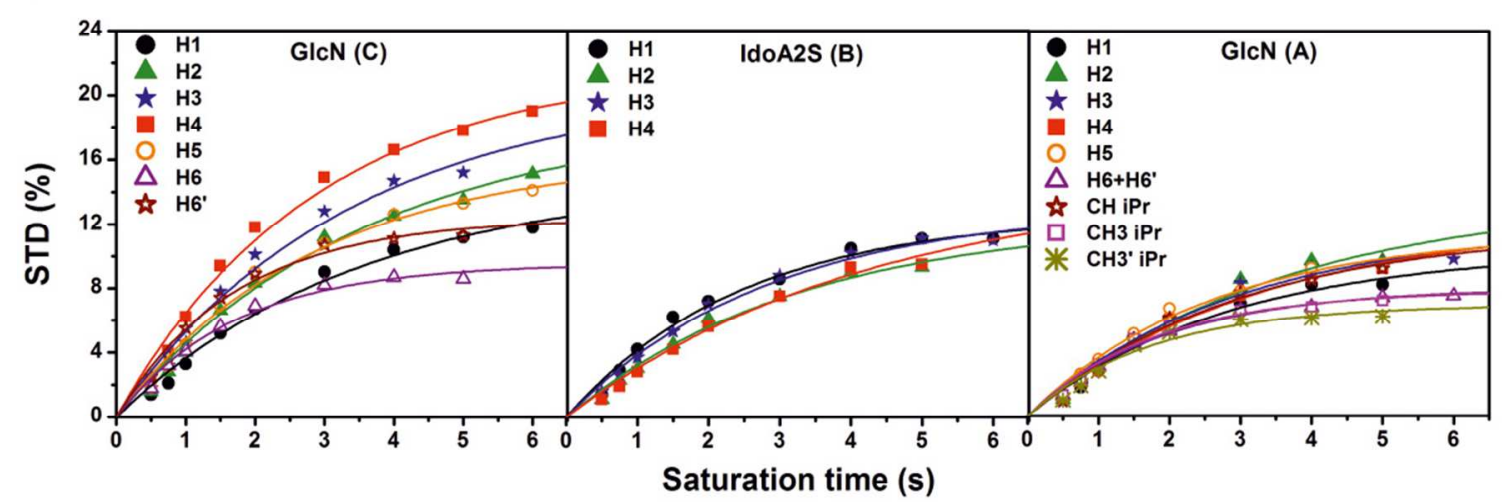

Figure 3. (a) Reference (top) and STD (bottom) spectra of the interaction of Tri1 with $\mathrm{Lg}$ ECD $\left(800 \mathrm{MHz}, 10^{\circ} \mathrm{C}, 2 \mathrm{~s}\right.$ saturation time). (b) Binding epitope of Tri1 from STD NMR experiments. The numbers denote the fraction of saturation (in \%) received from the protein by those ligand protons, relative to the maximum ligand STD signal (H4 of non-reducing GlcN ring; $100 \%$ ). Values close to $100 \%$ represent intimate contacts to the protein surface in the bound state. (c) STD build-up curves of ligand Tri1 in the presence of Lg ECD. The curves are divided by residue. The initial slopes of each curve are used to determine the binding epitope of the ligand. Similar data were obtained for Tri2-Tri8 (Supporting Information).

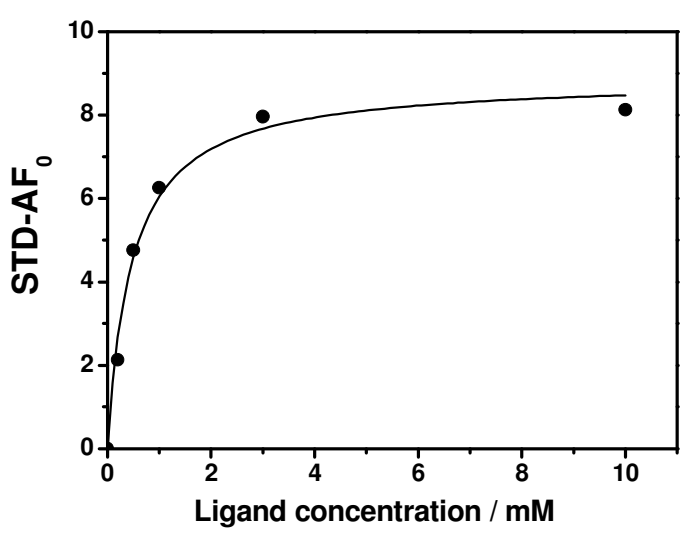

Figure 4. Binding isotherm of the interaction of Tri1 and $\operatorname{LgECD}\left(600 \mathrm{MHz}, 15{ }^{\circ} \mathrm{C}, 50 \mu \mathrm{M} \mathrm{Lg} \mathrm{ECD}\right)$. The curve was obtained following the protocol of STD initial slopes ${ }^{24}$, and the resulting $K_{D}$ was $490 \mu \mathrm{M}$. Tri2-Tri8 showed similar affinities for Lg ECD (see Supporting Information, Figure S3).

The analysis of binding epitopes of ligands Tri1-Tri8 from STD NMR, along with the observation of abolishment of binding to $\mathrm{Lg}$ ECD upon removal of the divalent cation, strongly supports that all the trisaccharides bind langerin at the
$\mathrm{Ca}^{2+}$-dependent binding pocket, through a classical coordination of the $\mathrm{Ca}^{2+}$ ion by the diequatorial hydroxyl groups $(\mathrm{OH} 3-\mathrm{OH} 4)$ at the non-reducing GlcN ring. This is supported by the strong STD intensities of protons $\mathrm{H} 3$ and $\mathrm{H} 4$ of residue C (Figures 3b and 3c, for Tri1 and Supporting Information Figure S2 for Tri2-Tri8). In addition, we confirmed the binding at the specific $\mathrm{Ca}^{2+}$ binding pocket by: (i) Surface Plasmon Resonance experiments in which Tri1 was shown to inhibit the binding of langerin to mannose, a langerin ligand that binds in the $\mathrm{Ca}^{2+}$ dependent binding pocket (see Supporting Information, Figure S5), and (ii) STD NMR competition experiment in which the $\mathrm{Ca}^{2+}$ dependent ligand 6-O-sulfate-galactose displaced Tri1 from the langerin $\mathrm{Ca}^{2+}$ binding pocket (Supporting Information, Figure S6).

Transferred NOESY experiments: $\mathrm{Lg}$ ECD recognizes the major conformers of the HEP-like trisaccharides Tri1-Tri8 in solution. We also carried out transferred NOESY experiments on the same samples used for the STD NMR experiments, containing the trisaccharide ligands, Lg ECD, and buffer with $\mathrm{Ca}^{2+}$. These samples were prepared with an appropriate ligand excess over protein (1:14 protein-to-ligand ratio) to be at good conditions for the observation of transferred-NOEs. Under these conditions, the observed averaged NOEs come mainly from the bound state, allowing the determination of the bioactive conformation or global geometry of the ligand in the Lg ECD-trisaccharide complex. The results were then compared to NOESY experiments on 
the free ligands, in the absence of protein, to reveal possible conformational changes accompanying the molecular recognition of the ligands by the receptor. Figure 5 shows expansions of NOESY and transferred-NOESY spectra of Tri1 (see also Supporting Information Figure S7).
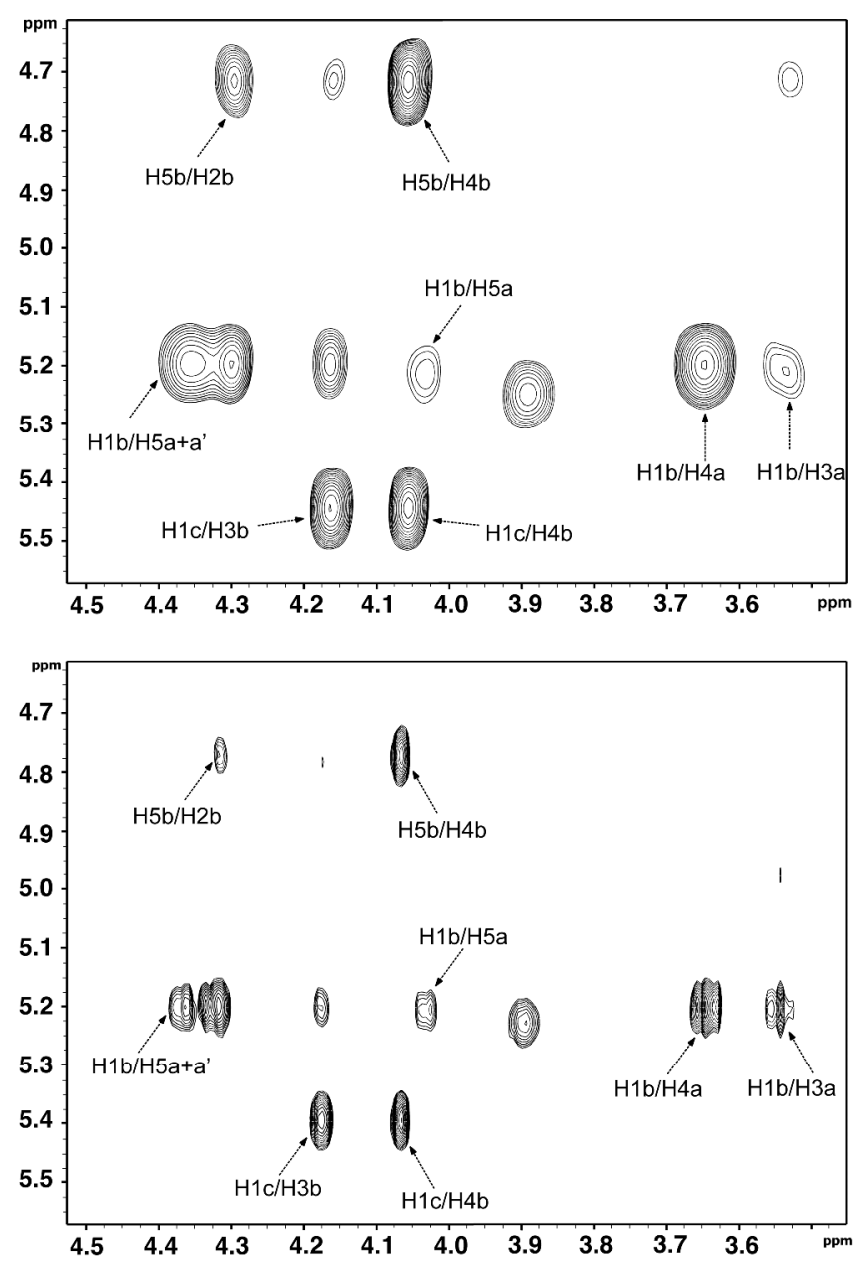

Figure 5. Top: expansion of the NOESY spectrum (mixing time $600 \mathrm{~ms}$ ) of ligand Tril (free state). Bottom: same expansion of the Transferred-NOESY spectrum (mixing time $200 \mathrm{~ms}$ ) of the same ligand in the presence of Lg ECD (bound state).

For HEP-like GAG oligosaccharides, the global geometry is determined by the conformations around the interglycosidic torsions $(\Phi, \Psi)$ of the GlcN-IdoA2S and IdoA2S-GlcN linkages $(\Phi=\mathrm{H} 1$ ' $-\mathrm{C} 1$ '-O4-C4, $\Psi=\mathrm{C} 1$ '-O4-C4-H4; primed and unprimed denote atoms on different consecutive residues). In addition, the global conformation can be affected by the particular conformational equilibrium of the central iduronate ring. This residue shows a polyconformational behavior, usually in chemical equilibrium between the chair conformations ${ }^{1} \mathrm{C}_{4}$ and ${ }^{4} \mathrm{C}_{1}$, and the skewed boat form ${ }^{2} \mathrm{~S}_{\mathrm{O}}$. The presence of the ${ }^{2} \mathrm{~S}_{O}$ conformer in solution was confirmed by the observation of its exclusive NOE between protons $\mathrm{H} 2$ and $\mathrm{H} 5$ of the iduronate ring (Figure 5, top).

In a previous NMR study we showed that in the free state, all the trisaccharides, Tri1-Tri8, displayed a significant population of ${ }^{2} \mathrm{~S}_{O}$ conformers in equilibrium with the ${ }^{1} \mathrm{C}_{4}$ chair. ${ }^{20}$ Furthermore, the series Tri1-Tri4 showed a larger population of ${ }^{2} S_{O}$ in in comparison to Tri5-Tri8, due to an effect of the 6-O-sulfate group at the reducing sugar ring, which is only present in the first trisaccharide series (Scheme 1). In the presence of $\mathrm{Lg} \mathrm{ECD}$, all the ligands showed the characteristic H2/H5 NOE (Figure 5, bottom, for Tri1; Supporting Information Figure S7 for Tri2-Tri8), indicating that the ${ }^{2} \mathrm{~S}_{\mathrm{O}}$ conformer of the central iduronate ring is present also in the bound state of the ligands in complex with langerin.

Table 1. Interglycosidic ${ }^{1} \mathrm{H}-{ }^{1} \mathrm{H}$ distances defining the global conformation of the trisaccharides in the bound state

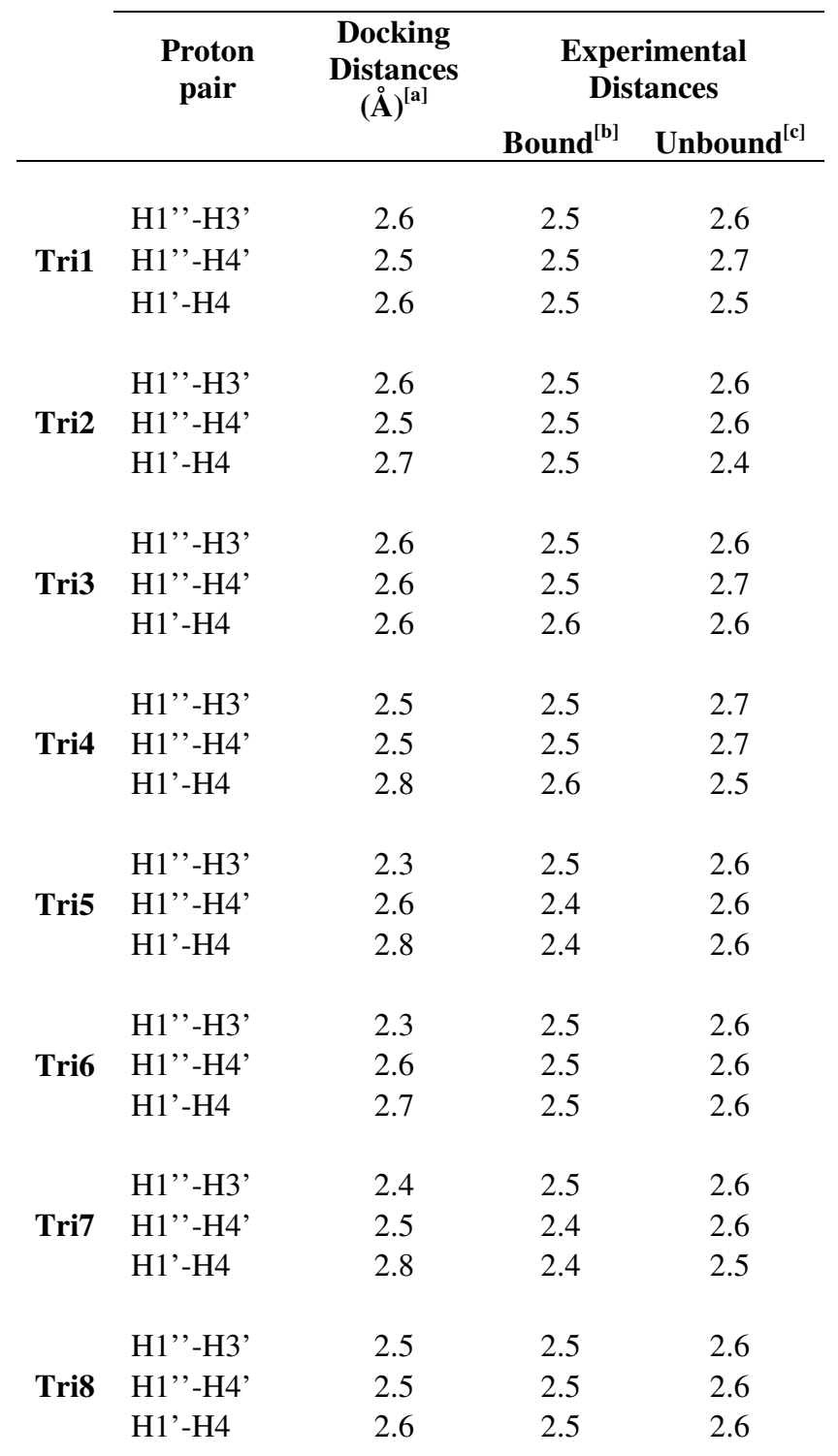

[a] Boltzmann $\mathrm{r}^{-6}$ averages $\left(\left\langle\mathrm{r}^{-6}\right\rangle^{-1 / 6}\right)$ over the best 20 ranked poses and $\mathrm{r}^{-6}$ weighted on the populations of ${ }^{1} \mathrm{C}_{4}$ and ${ }^{2} \mathrm{~S}_{\mathrm{O}}$ at $278 \mathrm{~K}$ (see Experimental Section). [b] Determined from trNOESY experiments considering the Isolated Spin Pair Approximation (see Experimental Section). [c] Values from reference ${ }^{20}$

Besides, the interglycosidic NOEs $\mathrm{H} 1^{\prime} / \mathrm{H} 3$ and $\mathrm{H} 1^{\prime} / \mathrm{H} 4$ for the GlcN(C)-IdoA2S(B) linkage, and $\mathrm{H} 1^{\prime} / \mathrm{H} 4$ and $\mathrm{H} 1^{\prime} / \mathrm{H} 6($ proR + proS $)$ for the $\operatorname{IdoA} 2 \mathrm{~S}(\mathrm{~B})-\mathrm{GlcN}(\mathrm{A})$ linkage, 
appeared intense in both, NOESY and transferred-NOESY experiments (Figure 5 and Figure S7 at the Supporting Information). A semiquantitative analysis of the diagnostic $\mathrm{H} 1$ '/H3 NOE of the closest glycosidic linkage to the binding pocket $(\mathrm{GlcN}(\mathrm{C})-\operatorname{IdoA} 2 \mathrm{~S}(\mathrm{~B}))$ shows little effect on this NOE upon binding to the protein (Supporting Information Table S1). These results substantiates that the syn- $\Psi$ conformation ( $\Psi$ torsions within the $-60^{\circ}$ and $+60^{\circ}$ range) is the major one for both glycosidic linkages, and that this preference does not change appreciably as a consequence of the binding to $\mathrm{Lg}$ ECD.

Next, we carried out a quantitative analysis of the NOESY and transferred-NOESY spectra. We experimentally determined key ${ }^{1} \mathrm{H}-{ }^{1} \mathrm{H}$ distances around the interglycosidic linkages of the trisaccharides in the bound state, from the transferred-NOESY experiments (Table 1), and compared them with the corresponding distances in the free state, taken from our previous work $^{20}$. The comparison corroborated that the global geometry of the eight trisaccharides, does not change as a consequence of the binding to Lg ECD (Table 1).

Table 2. Iduronate H2-H5 sigma-NOE $\left(s^{-1}\right)^{[a]}$ in the free and bound states, and their ratio to iduronate $\mathrm{H4}-\mathrm{H5}$ sigma-NOE

Free Bound Ratio Free Ratio Bound

$\begin{array}{lcccc}\text { Tri1 } & 5.27 & 7.45 & 0.32 & 0.26 \\ \text { Tri2 } & 5.29 & 13.36 & 0.33 & 0.36 \\ \text { Tri3 } & 4.32 & 13.70 & 0.30 & 0.31 \\ \text { Tri4 } & 5.77 & 16.49 & 0.33 & 0.28 \\ \text { Tri5 } & 2.64 & 5.80 & 0.17 & 0.16 \\ \text { Tri6 } & 3.03 & 4.28 & 0.20 & 0.16 \\ \text { Tri7 } & 1.98 & 5.62 & 0.17 & 0.14 \\ \text { Tri8 } & 1.42 & 6.40 & 0.15 & 0.11\end{array}$

[a] Cross relaxation rates (sigma NOE) were approximated by the ratio of the normalized NOE volume and the mixing time (see Experimental Section)

Finally, we analyzed the conformations of the central iduronate ring. To quantitatively compare between the bound and free states, we calculated the ratio between the cross relaxation rates $\left(\sigma_{\mathrm{NOE}}\right)$ of $\mathrm{H} 2-\mathrm{H} 5$ and $\mathrm{H} 5-\mathrm{H} 4$ contacts within this sugar ring ${ }^{29}$. The $\mathrm{H} 5-\mathrm{H} 4$ distance is an internal interprotonic separation within the iduronate ring that does not change between the ${ }^{1} \mathrm{C}_{4}$ and ${ }^{2} \mathrm{~S}_{\mathrm{O}}$ conformations, and helps to normalize the values. Differences in the $\mathrm{H} 2-\mathrm{H} 5 / \mathrm{H} 5-\mathrm{H} 4$ ratio should be detected if there were differences in the populations of the ${ }^{1} \mathrm{C}_{4}{ }^{2} \mathrm{~S}_{\mathrm{O}}$ equilibrium, between the free and bound states. The data in Table 2 show that the calculated ratios are fairly similar between both states. Furthermore, these ratios also reflect the different conformational behavior of the iduronate between the trisaccharides series Tri1-Tri4 and Tri5-Tri8 (Table 2, two last columns), as previously observed in the free state $^{20}$. The results show that in the state bound to Lg ECD there are also larger populations of ${ }^{2} S_{O}$ conformers for the Tri1-Tri4 series. All these experimental observations indicate that the protein does not influence the conformations of the iduronate residue in the bound state.

Interestingly, although the central iduronate ring makes significant contacts with the protein in the bound state (e.g., Figure 3 for Tri1), the trNOESY data indicate that Lg ECD can recognize the ligands in either ${ }^{1} \mathrm{C}_{4}$ or ${ }^{2} \mathrm{~S}_{\mathrm{O}}$ conformation (Figure 5 and Table 2). A similar behavior has been previously observed in a larger HEP-like hexasaccharide bound to the acidic fibroblast growth factor FGF-1, and it was proposed to be a way of alleviating the entropic penalty associated with the restriction on the degrees of freedom of the side chains caused by binding ${ }^{30}$. Likewise, Lg ECD has flexible residues involved in binding, e.g. the $\mathrm{Ca}^{2+}$ binding pocket is flanked by two lysine residues, K299 and K313, which can keep flexible enough in the bound state as to make contacts with the iduronate residue but still being able to accommodate the sugar ring in the two different conformations ${ }^{1} \mathrm{C}_{4}$ and ${ }^{2} \mathrm{~S}_{\mathrm{O}}$.

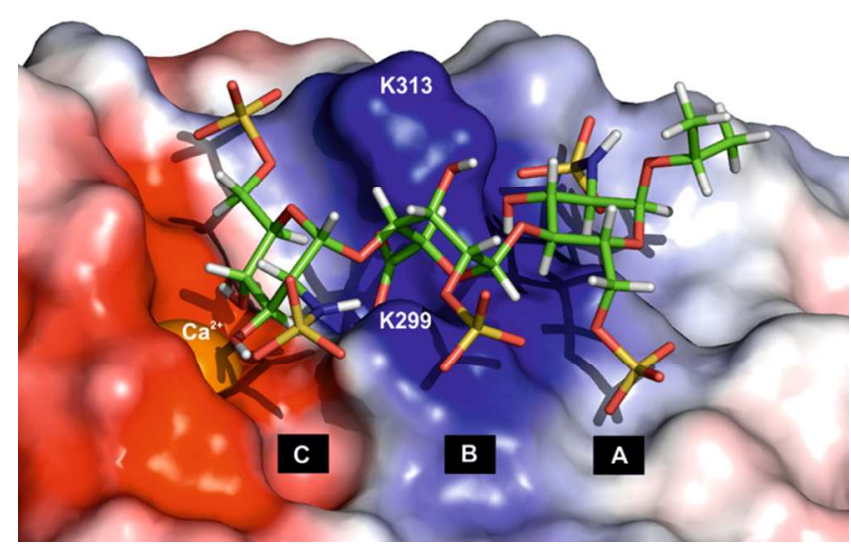

Figure 6. 3D molecular model of the complex of Tri1 with Lg ECD (main binding mode from docking calculations). The electrostatic potential is mapped onto the protein surface (blue: positive; red: negative). The key positively charged residues K299 and K313 are labeled.

Docking calculations: 3D molecular models of the $\mathrm{Ca}^{2+}$ dependent complexes of Tri1-Tri8 with langerin ECD. To get 3D molecular models of the complexes of the HEP-like trisaccharides with $\mathrm{Lg}$ ECD, we carried out docking calculations using the module Glide within the Schrödinger suite of programs ${ }^{31,32}$. The crystal structure of the complex of langerin-CRD with laminaritriose (pdb code 3P5H) was used as the starting point ${ }^{17}$. To define the limits of the grid box for energy calculations, the molecular model of Tri1 with the iduronate ring in ${ }^{1} \mathrm{C}_{4}$ conformation was placed in the $\mathrm{Ca}^{2+}$ dependent binding site by superimposing the backbones of the non-reducing end GlcN residue of Tri1 and the Glc residue of laminaritriose. In the X-ray structure of the complex with laminaritriose, the Glc residue contacts the $\mathrm{Ca}^{2+}$ ion through the oxygen atoms $\mathrm{O} 2$ and $\mathrm{O} 3$, however, to define properly the geometric center of the ligand within the box, Tri1 was oriented so that $\mathrm{O} 3$ and $\mathrm{O} 4$ were the contact atoms with the $\mathrm{Ca}^{2+}$ ion, guided by the binding epitope previously determined by STD NMR (Figure 3b). The ligand Tril was allowed to move through the whole space within the grid box, as no 
positional restraints were applied during the docking calculations.

We carried out Induced Fit Docking (IFD, see Supporting Information), to take into account movements of amino acid side chains in the binding pocket to better fit the shape of the ligand and to generate a more reliable receptor structure in the state bound to the Tri1 ligand. These highly charged ligands are expected to have strong influences on the conformations of protein side chains involved in binding in comparison to neutral or less charged carbohydrate molecules. Indeed, there is no known crystal structure of langerin bound to such highly charged HEP ligands in the $\mathrm{Ca}^{2+}$ binding site. Tri2-Tri8 ligands were then docked onto the IFD-refined receptor using standard flexible docking procedure.

The calculations showed very good convergence for all the eight trisaccharides (Supporting Information Figure S8), giving rise to a well-defined highly populated main binding mode, plus a low populated secondary binding mode. In the main binding mode (Figure 6) the major contacts with the protein are through the non-reducing end $(\mathrm{GlcN}(\mathrm{C}))$, via coordination of $\mathrm{Ca}^{2+}$ with the hydroxyl groups $\mathrm{OH} 3$ and $\mathrm{OH} 4$. This is in very good agreement with the STD NMR observations, which showed that $\operatorname{GlcN}(\mathrm{C})$ established the shortest spatial contacts with the protein (Figure $3 b$ ). On the other hand, in this binding mode, the remaining residues ( $\mathrm{A}$ and B) are oriented towards the positively charged side chains of K299 and K313 (Figure 6), making secondary contacts with the surface of the protein, explaining the saturation received by those moieties of the ligands in the STD NMR experiments (Figure 3b). The superimposition of the eight main solutions from docking calculations for the trisaccharides both in ${ }^{1} \mathrm{C}_{4}$ and ${ }^{2} \mathrm{~S}_{\mathrm{O}}$ conformations revealed that all of them bind $\mathrm{Lg}$ ECD in very similar binding modes (Figure 7), again in agreement with the STD NMR results.

(a)

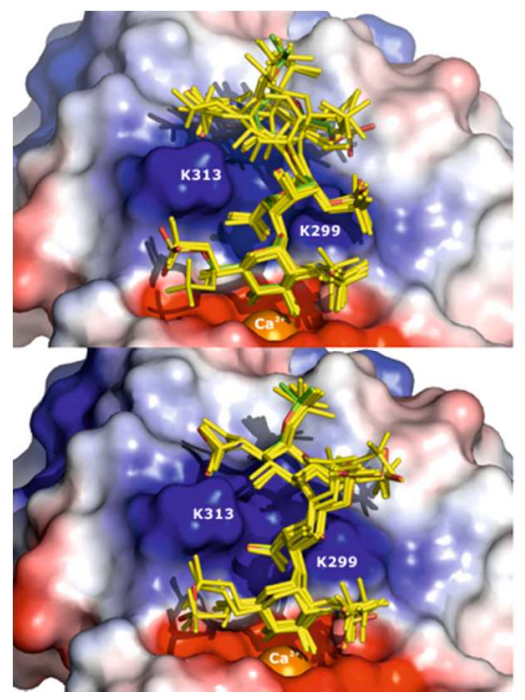

Figure 7. Main binding modes of Tri1 (colored by atom type; green carbon, red oxygen) with $\mathrm{Lg} \mathrm{ECD}$, for the two conformers of the central iduronate ring, ${ }^{1} \mathrm{C}_{4}$ (a), and ${ }^{2} \mathrm{~S}_{\mathrm{O}}(\mathrm{b})$, superimposed with the binding modes of Tri2-Tri8 (in yellow)
The calculations hence corroborated, as observed in the NMR experiments, that the different patterns of sulfation of Tri1Tri8 do not influence their mode of binding to Lg ECD. In the main binding mode, the coordination of $\mathrm{Ca}^{2+}$ by the $\mathrm{OH} 3$ and $\mathrm{OH} 4$ hydroxyl groups of the non-reducing GlcN ring explains the $\mathrm{Ca}^{2+}$ dependency of the interaction, observed in the STD NMR experiments. Alongside that main element of proteinligand contacts, all the trisaccharides characteristically showed a double salt bridge involving the coordination of the carboxylate group of the central iduronate ring with the ammonium groups of the side chains of K299 and K313 (Figure 8a). This interaction makes the non-reducing end glucosamine ring to bind in a slightly twisted orientation in comparison with neutral mannose ending ligands (Supporting Information Figure S9).

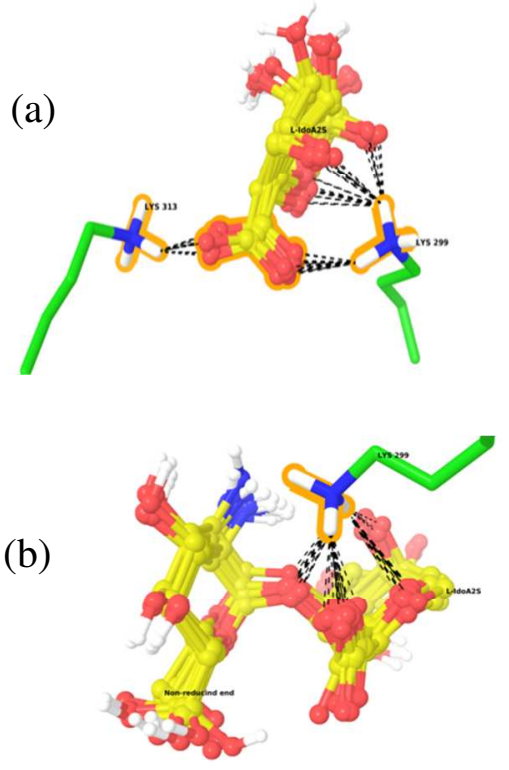

Figure 8. Common structural motifs of the best docking poses obtained for the 16 trisaccharide models ( 8 with the IdoA2S ring in ${ }^{1} \mathrm{C}_{4}$ chair and 8 in ${ }^{2} \mathrm{~S}_{\mathrm{O}}$ skew-boat conformations). (a) K299-COO'(L-IdoA2S)-K313 salt bridge. (b) K299 ammonium group occupying so-called type A binding site specific for $\mathrm{Ca}^{2+}$ cations ${ }^{33}$.

None of these key structural elements for the recognition of the HEP trisaccharides by Lg ECD involve the participation of any of the variable sulfate groups of the trisaccharides $(\mathrm{N}-$ and 6-O-sulfates of residue $\mathrm{A}$, and 6-O-sulfate of residue $\mathrm{C}$, see Scheme 1), explaining why the differences in sulfation patterns between Tri1-Tri8 do not have any significant impact on the interaction with Lg ECD. Finally, in all cases, the ammonium group of K299 occupies the region below the plane of the central iduronate ring (Figure $8 \mathrm{~b}$ ) and the nonreducing glucosamine ring. This location has been previously identified as a specific site for the interaction with $\mathrm{Ca}^{2+}$ ions of HEP oligosaccharides ${ }^{33-35}$. In this case, instead of $\mathrm{Ca}^{2+}$, the positively charged ammonium group coordinates the oxygen O6, O5, and $\mathrm{O} 4$ of the iduronate ring (Figure 8b).

To validate and test the dynamical stability of the 3D molecular models obtained from docking calculations, we carried out long MD simulations (100 ns) in explicit water on the complex of Lg ECD with Tri1. The starting structure 
consisted of the full trimeric receptor including one copy of the best ranked docking solution of Tri1 in each of the three $\mathrm{Ca}^{2+}$ binding sites. This increases three-fold the conformational space sampling for a given simulation time. The analysis was focused on the level of flexibility of Tri1 in the bound state by following the RMSd per sugar residue backbone with respect to the protein binding site, and the conformational space sampled around the $\Phi, \Psi$ torsions. The RMSd per sugar residue clearly highlighted, on average, a significantly higher mobility of the reducing end GlcN ring (residue A) with respect to the binding site, in all the three monomers (Supporting Information Figures S11-S13). In addition, a much larger flexibility of the $\Phi, \Psi$ torsions at the IdoA2S-GlcN linkage was observed (Figure S14 at the Supporting Information). This supports a larger separation of this residue from the protein surface by variation of both the orientation of the principal axis of the ligand with respect to an imaginary plane defined by K299 and K313 (see Supporting Information, Figure S13) and the flexibility of the ligand at the reducing end. In contrast, the non-reducing $\mathrm{GlcN}$ ring stays well fixed on the $\mathrm{Ca}^{2+}$ site along the whole simulation. This is in very good agreement with the STD NMR epitope, and verifies the stability of the $3 \mathrm{D}$ molecular model of the complex obtained by docking calculations.

The binding of small sulfated oligosaccharides in the $\mathrm{Ca}^{2+}$ dependent binding site of langerin, like 6-sulfated galactosides, has been previously reported ${ }^{13,16}$. For sulfated ligands with a galactose sugar stereochemistry, the side chains of K299 and K313 play a key role in the stabilization of the complex by establishing an electrostatic bridge interaction with the O-sulfate group at position 6 of the ligand. However, in the case of HEP-like oligosaccharides, with a glucose stereochemistry at the non-reducing end, the oligosaccharide is oriented in a different way making the electrostatic bridge interaction to take place with the carboxylate group of the adjacent iduronate ring (Figure 8a, and Supporting Information Figure S10 for the comparison of the binding modes of Tri1 and sulfo-LacNAc). Besides, an additional contribution comes from the favorable interaction of the positively charged ammonium group in the $\mathrm{Ca}^{2+}$ specific HEP binding site located below the plane of the iduronate ring ${ }^{33}$ (Figure $8 b$ ). In both cases, the presence of the two positively charged lysine side chains at the edge of the $\mathrm{Ca}^{2+}$ binding site in langerin confers the ability of binding negatively charged oligosaccharides.

STD NMR experiments (III): the interaction of a HEP-like hexasaccharide with langerin $\mathrm{ECD}$ is $\mathrm{Ca}^{2+}$ independent. We have shown that the small HEP-like trisaccharides Tri1-Tri8 interact with $\mathrm{Lg}$ ECD in a different mode than large oligosaccharides $(6 \mathrm{kDa})$ derived from natural heparin. We then decided to study the binding of a larger synthetic HEPlike hexasaccharide, Hexa9, (Scheme 1) ${ }^{21}$. This molecule harbors a sulfation pattern typical of the so-called regular regions of heparin, plus an additional O-sulfate group at position 4 of the non-reducing glucosamine ring (Scheme 1). The latter modification is expected to preclude Hexa9 from binding at the $\mathrm{Ca}^{2+}$ specific carbohydrate binding site of $\mathrm{Lg}$ $\mathrm{ECD}$, as the $\mathrm{OH} 4$ group of the required diequatorial $\mathrm{OH} 3-\mathrm{OH} 4$ configuration is no longer present, and it is substituted by a bulky charged functional group. STD NMR spectra of a sample containing an excess of the hexasaccharide Hexa9 in the presence of $\mathrm{Lg}$ ECD are shown in Figure 9.

In the presence of $4 \mathrm{mM} \mathrm{Ca}^{2+}$ ions, the experiment showed strong STD signals indicative of binding of Hexa9 to the protein (Figure 9a,b). Interestingly, and in contrast to what was observed for trisaccharides Tri1-Tri8, the removal of $\mathrm{Ca}^{2+}$ ions from the sample by sequestration with a large excess of EDTA, this time did not have an effect on the binding to $\mathrm{Lg}$ ECD, as strong signals were observable in the STD spectrum (Figure 9c,d). This result strongly supports that the binding of the hexasaccharide Hexa9 to Lg ECD takes place in binding site different to the $\mathrm{Ca}^{2+}$ specific one.
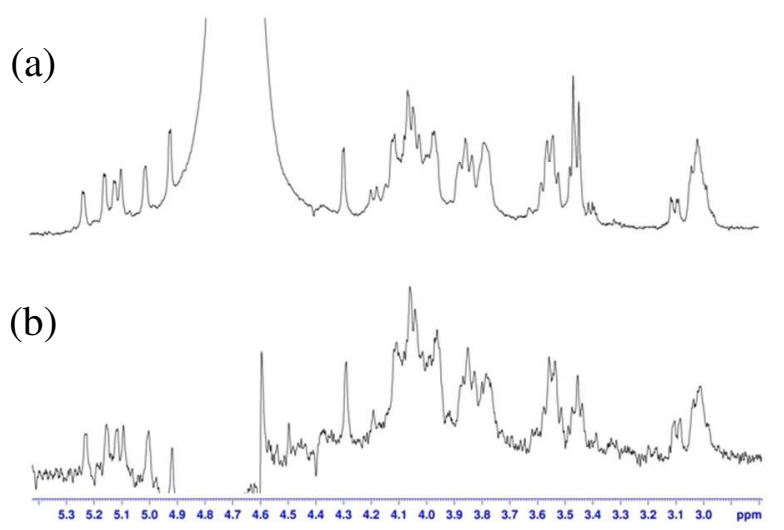

(c)
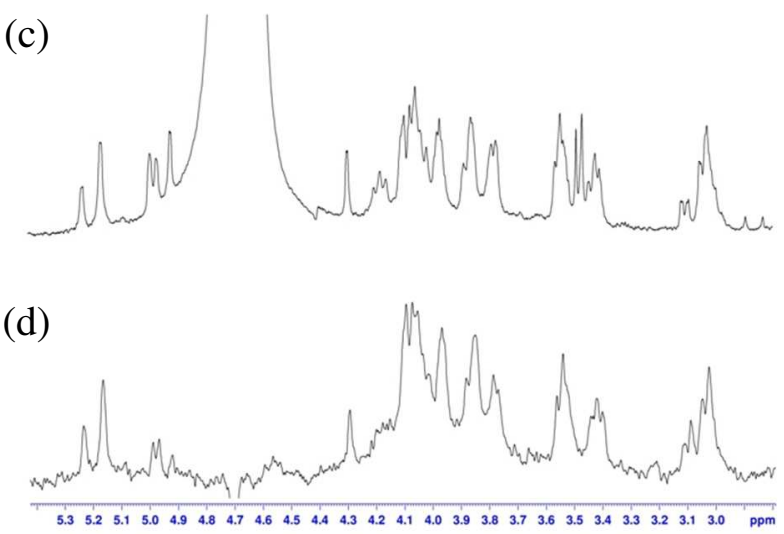

Figure 9. The hexasaccharide Hexa9 binds Lg ECD in a different binding mode in comparison to trisaccharides Tri1Tri8, in a $\mathrm{Ca}^{2+}$ independent manner. (a) Reference ${ }^{1} \mathrm{H}$ NMR spectrum of Hexa9 in the presence of $\mathrm{Lg}$ ECD in a buffer containing $4 \mathrm{mM} \mathrm{Ca}^{2+}$ ions. (b) STD NMR spectrum of that sample. (c) Reference ${ }^{1} \mathrm{H}$ NMR spectrum of Hexa9 in the presence of $\mathrm{Lg}$ ECD in a buffer containing $4 \mathrm{mM} \mathrm{Ca}^{2+}$ ions and $10 \mathrm{mM}$ EDTA to sequester the divalent cations. (d) STD NMR of that sample.

The strong signal overlap of the spectra of Hexa9 (Figure 9) precluded a detailed determination of its binding epitope for its interaction with Lg ECD. Nevertheless, a couple of features emerged clearly from the data: first, no clear main contact with a specific sugar ring of the ligand is detected, yet an homogeneous distribution of the saturation along the whole ligand is observed, indicative of binding in a longitudinal 
orientation parallel to the protein surface (although spin diffusion within the ligand cannot be discarded a priori and it would spread the saturation along the molecule, the longitudinal orientation of Hexa9 in the bound state is strongly supported by the fact that protons of both terminal reducing and non-reducing residues show similar STD intensities); and second, there were changes in the chemical shifts of Hexa9 (particularly of the anomeric protons, Figure 9) upon removal of $\mathrm{Ca}^{2+}$ ions. This is a phenomenon related to the specific interactions of the hexasaccharide with the divalent cations in the free state, a behavior that has been previously described for synthetic equivalent hexasaccharides ${ }^{33}$.

The STD NMR data on the molecular recognition of hexasaccharide Hexa9 by Lg ECD are hence strongly supporting an interaction similar to that described previously for $6 \mathrm{kDa} \mathrm{HEP}$. In this proposed binding mode, the hexasaccharide occupy part of the groove formed between two adjacent carbohydrate recognition domains (see Figure 1). This groove is lined by positively charged side chains of lysine residues, which accommodate very well the negatively charged groups of the hexasaccharide Hexa9, making unnecessary the coordination of any hydroxyl groups of the ligand with $\mathrm{Ca}^{2+}$ on the surface of the protein for the binding to $\mathrm{Lg}$ ECD to occur. The longitudinal orientation along the groove agrees well with the homogenous distribution of protein saturation transferred along the whole ligand in the STD NMR experiment.

This is the first time, to our knowledge, that langerin is reported to be able to bind the same type of sulfated ligand, HEP oligosaccharides, in two different binding sites depending on the ligand size. Previously, small 6-sulfated galactosides were reported to bind to the $\mathrm{Ca}^{2+}$ specific langerin binding site, and large (6 kDa) HEP was shown to bind at the binding site located at the multimerization interface between langerin monomers ${ }^{18}$. Here we demonstrate that small HEPlike oligosaccharides can also bind to the $\mathrm{Ca}^{2+}$ dependent binding site, although in a different orientation than sulfated galactosides due to the differences in sugar stereochemistries. On the other hand, the use of a synthetic hexasaccharide with a structural modification precluding its binding to the $\mathrm{Ca}^{2+}$ binding pocket, allowed us to demonstrate that for a HEP oligosaccharide length of a least six sugar units, the binding takes place in the previously identified second binding site specific for HEP oligosaccharides located at the interfaces of multimerization between the CRD units in the langerin trimeric state.

Natural GAG polysaccharides, present at the extracellular matrix as long chains of proteoglycans, have the required $\mathrm{OH} 3-\mathrm{OH} 4$ diequatorial structural requirement at the nonreducing end, so they can bind in either mode. However, for a very long GAG chains the number of possible interacting sequences with the groove of the langerin trimer is significantly much higher in comparison to only one nonreducing end residue per chain. In that sense, the binding at the $\mathrm{Ca}^{2+}$ specific binding pocket, studied in the present work with the use of the synthetic trisaccharides, is very likely to constitute an additional stabilizing interaction to facilitate the approach of langerin trimers in the face-to-face homotypic interactions proposed in previous putative models of langerin contribution to the ultrastructural organizations of the Birbeck granules $^{18,36}$.

\section{CONCLUSIONS}

NMR spectroscopy combined with cross-linking experiments and molecular modeling techniques demonstrates that langerin binds HEP oligosaccharides in two different binding sites depending on the ligand size. Small HEP-like trisaccharides (Tri1-Tri8) bind with comparable affinities in a $\mathrm{Ca}^{2+}$ dependent way, on the $\mathrm{Ca}^{2+}$ specific binding site. The key structural elements for molecular recognition in a $\mathrm{Ca}^{2+}$ dependent manner have been identified and shown to be shared by all the 8 ligands, explaining the absence of impact on binding of their different substitution patterns. In contrast to sulfated galactosides, the two key lysine residues at the edge of the $\mathrm{Ca}^{2+}$ specific binding site do not bind the sulfate groups, but stabilize the complex through bridge interaction with the carboxylate group of the iduronate residue adjacent to the non-reducing end glucosamine ring.

Heparin cross-linking experiments validate the previously proposed binding site on langerin trimers for large $(6 \mathrm{kDa})$ HEP oligosaccharides, in which the binding takes place at a positively charged groove located at the interface formed by 2 CRDs and the neck domain. STD NMR experiments show that, in contrast to the small HEP-like trisaccharides, a hexasaccharide containing the regular sulfation pattern of heparin, plus a sulfate group at position 4 of the non-reducing end (preventing binding to the $\mathrm{Ca}^{2+}$ binding pocket), binds langerin at the langerin binding groove for long oligosaccharides, in a $\mathrm{Ca}^{2+}$ independent manner.

\section{ASSOCIATED CONTENT}

Supporting Information. Peptide sequencing data, full set of NMR data for the trisaccharides Tri2-Tri8, affinity data for the trisaccharides, SPR competition data for Tri1, along with extended set of results from docking, as well as the conditions for the molecular modeling calculations are supplied as Supporting. "This material is available free of charge via the Internet at http://pubs.acs.org."

\section{AUTHOR INFORMATION}

\section{Corresponding Author}

pedro.nieto@iiq.csic.es

j.angulo@uea.ac.uk

\section{Author Contributions}

The manuscript was written through contributions of all authors. All authors have given approval to the final version of the manuscript.

\section{ACKNOWLEDGMENT}

We thank the CSIC (Grant No. 201180E021), the Spanish Ministry of Science and Innovation (Grant No. CTQ2009-07168), the Junta de Andalucia (Grant No. P07-FQM-02969, and "Incentivo a Proyecto Internacional") and the European Union (FEDER support and Marie Curie Reintegration Grant) for financial support. J.C.M. acknowledges financial support from CSIC. J.A. acknowledges financial support from the MICINN through the Ramon y Cajal program, and the School of Pharmacy of the University of East Anglia. Access to the $800 \mathrm{MHz}$ facilities of the Unitat de RMN d'alt camp of the University of Barcelona is acknowledged. FF thanks the Institut Universitaire de France for 
financial support. This work used the platforms of the Grenoble Instruct centre (ISBG; UMS 3518 CNRS-CEA-UJF-EMBL) with support from FRISBI (ANR-10-INSB-05-02) and GRAL (ANR10-LABX-49-01) within the Grenoble Partnership for Structural Biology (PSB). We thank J.P. Andrieu for access to the protein Nterminal sequencing facility, and M.J. Garcia-Jimenez for helping in the affinity measurements.

\section{ABBREVIATIONS}

Lg ECD, langerin extracellular domain; LCs, Langerhans cells; DCs, dendritic cells; HEP, heparin; HS, heparan sulfate; STD, saturation transfer Difference; IFD induced fit docking

\section{REFERENCES}

(1) Fithian, E.; Kung, P.; Goldstein, G.; Rubenfeld, M.; Fenoglio, C.; Edelson, R. Proc. Natl. Acad. Sci. U. S. A. 1981, $78,2541$.

(2) Patterson, B. K.; Landay, A.; Siegel, J. N.; Flener, Z.; Pessis, D.; Chaviano, A.; Bailey, R. C. The American journal of pathology 2002, 161, 867 .

(3) Klareskog, L.; Tjernlund, U. M.; Forsum, U.; Peterson, P. A. Nature 1977, 268, 248.

(4) Rowden, G.; Lewis, M. G.; Sullivan, A. K. Nature 1977, 268, 247.

(5) Valladeau, J.; Ravel, O.; Dezutter-Dambuyant, C.; Moore, K.; Kleijmeer, M.; Liu, Y.; Duvert-Frances, V.; Vincent, C.; Schmitt, D.; Davoust, J.; Caux, C.; Lebecque, S.; Saeland, S. Immunity 2000, 12, 71. $392,245$.

(6) Banchereau, J.; Steinman, R. M. Nature 1998,

(7) Hunger, R. E.; Sieling, P. A.; Ochoa, M. T.; Sugaya, M.; Burdick, A. E.; Rea, T. H.; Brennan, P. J.; Belisle, J. T.; Blauvelt, A.; Porcelli, S. A.; Modlin, R. L. The Journal of Clinical Investigation 2004, 113, 701.

(8) Stoitzner, P.; Romani, N. European Journal of Immunology 2011, 41, 2526.

(9) Birbeck, M. S.; Breathnach, A. S.; Everall, J. D. The Journal of Investigative Dermatology 1961, 37, 51.

(10) de Witte, L.; Nabatov, A.; Pion, M.; Fluitsma, D.; de Jong, M. A. W. P.; de Gruijl, T.; Piguet, V.; van Kooyk, Y.; Geijtenbeek, T. B. H. Nat Med 2007, 13, 367.

(11) Chabrol, E.; Thépaut, M.; Dezutter-Dambuyant, C.; Vivès, C.; Marcoux, J.; Kahn, R.; Valladeau-Guilemond, J.; Vachette, P.; Durand, D.; Fieschi, F. Biophys J 2015, 108, 666.

(12) Drickamer, K. Nature 1992, 360, 183.

(13) Feinberg, H.; Powlesland, A. S.; Taylor, M. E.; Weis, W. I. J Biol Chem 2010, 285, 13285

(14) Galustian, C.; Park, C. G.; Chai, W.; Kiso, M.; Bruening, S. A.; Kang, Y. S.; Steinman, R. M.; Feizi, T. Int Immunol 2004, 16, 853.

(15) Holla, A.; Skerra, A. Protein Eng Des Sel 2011, 24,659 .

(16) Feinberg, H.; Rowntree, T. J. W.; Tan, S. L. W.; Drickamer, K.; Weis, W. I.; Taylor, M. E. J Biol Chem 2013, 288, 36762.
(17) Feinberg, H.; Taylor, M. E.; Razi, N.; McBride, R.; Knirel, Y. A.; Graham, S. A.; Drickamer, K.; Weis, W. I. J Mol Biol 2011, 405, 1027.

(18) Chabrol, E.; Nurisso, A.; Daina, A.; VassalStermann, E.; Thepaut, M.; Girard, E.; Vivès, R. R.; Fieschi, F. PloS one 2012,7 , e50722.

(19) Thépaut, M.; Valladeau, J.; Nurisso, A.; Kahn, R.; Arnou, B.; Vivès, C.; Saeland, S.; Ebel, C.; Monnier, C.; DezutterDambuyant, C.; Imberty, A.; Fieschi, F. Biochemistry 2009, 48, 2684.

(20) Muñoz-García, J. C.; López-Prados, J.; Angulo, J.; Díaz-Contreras, I.; Reichardt, N.; de Paz, J. L.; Martín-Lomas, M.; Nieto, P. M. Chemistry - A European Journal 2012, 18, 16319.

(21) Maza, S.; Macchione, G.; Ojeda, R.; LopezPrados, J.; Angulo, J.; de Paz, J. L.; Nieto, P. M. Org Biomol Chem $2012,10,2146$.

(22) Vivès, R. R.; Crublet, E.; Andrieu, J.-P.; Gagnon, J.; Rousselle, P.; Lortat-Jacob, H. Journal of Biological Chemistry 2004, 279, 54327.

(23) Mayer, M.; Meyer, B. Angew. Chem. Int. Ed. $1999,38,1784$

(24) Angulo, J.; Enriquez-Navas, P. M.; Nieto, P. M. Chem-Eur J 2010, 16, 7803.

(25) Jeener, J.; Meier, B. H.; Bachmann, P.; Ernst, R. R. The Journal of Chemical Physics 1979, 71, 4546.

(26) Wagner, R.; Berger, S. Journal of Magnetic Resonance, Series A 1996, 123, 119.

(27) Clore, G. M.; Gronenborn, A. M. J. Magn. Reson. 1985, 61, 158.

(28) Mayer, M.; James, T. L. J. Am. Chem. Soc $2004,126,4453$

(29) Guerrini, M.; Guglieri, S.; Casu, B.; Torri, G.; Mourier, P.; Boudier, C.; Viskov, C. Journal of Biological Chemistry 2008, 283, 26662.

(30) Canales, A.; Angulo, J.; Ojeda, R.; Bruix, M.; Fayos, R.; Lozano, R.; Gimenez-Gallego, G.; Martin-Lomas, M.; Nieto, P. M.; Jimenez-Barbero, J. J. Am. Chem. Soc. 2005, 127, 5778.

(31) Friesner, R. A.; Banks, J. L.; Murphy, R. B.; Halgren, T. A.; Klicic, J. J.; Mainz, D. T.; Repasky, M. P.; Knoll, E. H.; Shelley, M.; Perry, J. K.; Shaw, D. E.; Francis, P.; Shenkin, P. S. Journal of Medicinal Chemistry 2004, 47, 1739.

(32) Halgren, T. A.; Murphy, R. B.; Friesner, R. A.; Beard, H. S.; Frye, L. L.; Pollard, W. T.; Banks, J. L. Journal of Medicinal Chemistry 2004, 47, 1750.

(33) Angulo, J.; De Paz, J. L.; Nieto, P. M.; MartinLomas, M. Israel Journal of Chemistry 2000, 40, 289.

(34) Chevalier, F.; Angulo, J.; Lucas, R.; Nieto, P. M.; Martin-Lomas, M. European Journal of Organic Chemistry 2002, 2367.

(35) Chevalier, F.; Lucas, R.; Angulo, J.; MartinLomas, M.; Nieto, P. M. Carbohydrate Research 2004, 339, 975.

(36) Lenormand, C.; Spiegelhalter, C.; Cinquin, B.; Bardin, S.; Bausinger, H.; Angenieux, C.; Eckly, A.; Proamer, F.; Wall, D.; Lich, B.; Tourne, S.; Hanau, D.; Schwab, Y.; Salamero, J.; de la Salle, H. Plos One 2013, 8. 